\title{
СРАВНИТЕЛЬНЫЙ АНАЛИЗ СТЕРИЛИЗАТОРОВ НА ОСНОВЕ ПЕРИОДИЗАЦИИ ИХ ИСПОЛЬЗОВАНИЯ
}

\section{V.V. Shakhov, I.E. Fedotova, L.V. Tashmatova, O.V. Matsneva, T.M. Khromova}

\section{COMPARATIVE ANALYSIS OF STERILIZERS ON THE BASIS OF PERIODIZATION OF THEIR USE}

Шахов В.В. - мл. науч. сотр. лаб. биотехнологии Всероссийского НИИ селекции плодовых культур, Орловская обл., Орловский р-н, д. Жилина. E-mail: mentosvad@vniispk.ru

Федотова И.Э. - канд. с.-х. наук, доц., зав. каф. почвоведения и прикладной биологии Орловского государственного университета им. И.С. Тургенева, г. Орел.

E-mail: fedotovaie@mail.ru

Ташматова Л.В. - канд. с.-х. наук, зав. лаб. биотехнологии Всероссийского НИИ селекции плодовых культур, Орловская обл., Орловский р-н, д. Жилина.

E-mail: tashmatova@vniispk.ru

Мацнева О.В. - науч. сотр. лаб. биотехнологии Всероссийского НИИ селекции плодовых культур, Орловская обл., Орловский р-н, д. Жилина. E-mail:mazneva@vniispk.ru

Хромова Т.М. - мл. науч. сотр. лаб. биотехнологии Всероссийского НИИ селекции плодовых культур, Орловская обл., Орловский р-н, д. Жилина. E-mail: gavrikovatatyana@mail.ru

Обязательным условием введения исходного материала в культуру in vitro является его стерилизация, поэтому для обеззараживания первичных эксплантов проводят поверхностную обработку. Необходимо подбирать определенные типы стерилизующих агентов, которые не повреждали бы их и обеспечивали максимальную стерильность. Цель исследований - изучение эфффективности стерилизующих агентов на этапе введения сортов вишни в культуру in vitro в 2018 и 2019 годах. Опьт проводился на базе лаборатории биотехнологии ВНИИСПК (Всероссийский научно-
Shakhov V.V. - Junior Staff Scientist, Lab. of Biotechnology, All-Russian Scientific Research Institute of Fruit Crops Breeding, Orel Region, Orel District, V. Zhilina.

E-mail: mentosvad@vniispk.ru

Fedotova I.E. - Cand. Agr. Sci., Head, Chair of Soil Science and Applied Biology, Orel State University named after I.S. Turgenev, Orel.

E-mail: fedotovaie@mail.ru

Tashmatova L.V. - Cand. Agr. Sci., Head, Lab. of Biotechnology, All-Russian Scientific Research Institute of Fruit Crops Breeding, Orel Region, Orel District, V. Zhilina.

E-mail: tashmatova@vniispk.ru

Matsneva O.V. - Staff Scientist, Lab. of Biotechnology, All-Russian Scientific Research Institute of Fruit Crops Breeding, Orel Region, Orel District, V. Zhilina.

E-mail: mazneva@vniispk.ru

Khromova T.M. - Junior Staff Scientist, Lab. of Biotechnology, All-Russian Scientific Research Institute of Fruit Crops Breeding, Orel Region, Orel District, V. Zhilina.

E-mail: gavrikovatatyana@mail.ru

исследовательский институт селекции плодовых культур, г. Орел) в 2018 и 2019 годах. Объектами исследования являлись сорта: Ровесница, Тургеневка, Новелла, Быстринка, Ливенская, Орлица, Бусинка. Исходным материалом служили экспланты, изолированные из верхушечных и боковых почек с однолетних побегов в фразу начала выхода из покоя (март). Основными стерилизующими агентами являлись 0,1\% раствор мертиолата, $12 \%$ раствор перекиси водорода и раствор белизны (гипохлорит натрия с содержанием активного хлора 95,2 \%) в соотношении 1:2 и 0,1 \% рас- 
твор сулемы. Перед введением реагентов побеги ставили на отрастание. Установлено, что для получения стерильных и жизнеспособных эксплантов наиболее эфрфективным стерилизующим агентом для всех изученных сортов вишни оказался 0,1 \% раствор мертиолата (94,6 \%), но в следующем проведенном исследовании наиболее эфрфективным стерилизующим агентом является сулема 0,1 \% (99,9\%). Применение других стерилизующих агентов не оказало должного воздействия. Для сортов Орлица и Быстринка выявлена высокая эфффективность стерилизации при обработке всеми используемыми агентами. Таким образом, была выявлена зависимость влияния различных сроков введения на жизнеспособность эксплантов при их стерилизации в условиях in vitro.

Ключевые слова: вишня, стерилизующий агент, in vitro, жизнеспособность, некроз, контаминация.

An obligatory condition for the introduction of initial material into the culture in vitro is its sterilization so for the disinfection of primary explants, surface treatment is carried out. It is necessary to select certain types of sterilizing agents that would not damage them and ensure maximum sterility. The purpose of the research was to study the effectiveness of sterilizing agents at the stage of introduction of cherry varieties into culture in vitro in 2018 and 2019. The experiment was carried out on the basis of the Laboratory of Biotechnology ARRIFCS (All-Russian Research Institute of Fruit Crops Selection, Orel) in 2018 and 2019. The objects of the study were the varieties: Rovestnitsa, Turgenevka, Novella, Bystrinka, Livenskaya, Orlitsa, Businka. The initial materials were explants isolated from apical and lateral buds from annual sprouts in the phase of the beginning of the exit from repose (March). The main sterilizing agents were $0.1 \%$ mertiolate solution, $12 \%$ hydrogen peroxide solution and whiteness solution (sodium hypochlorite with $95.2 \%$ active chlorine content) in a ratio of $1: 2$ and $0.1 \%$ sulema solution. The sprouts were placed on regrowth before the introduction. It was found that for sterile and viable explants the most effective sterilizing agent for all studied varieties of cherries was $0.1 \%$ solution of mertiolate $94.6 \%$, but in the following study the most effective steriliz- ing agent is sulema $99.9 \%$. The use of other sterilizing agents didn't have a desired effect. For varieties Orlitsa and Bystrinka high efficiency of sterilization at processing by all used agents is discovered. Thus, the dependence of the influence of different periods of introduction on the viability of explants during their sterilization in vitro was revealed.

Keywords: cherry, sterilizing agent, in vitro, viability, necrosis, contamination.

Введение. В настоящее время возникла острая необходимость ускорения селекционного процесса, что особенно актуально для многолетних плодовых растений. В улучшении классического селекционного процесса большую значимость обретает применение биотехнологических способов и приемов, в частности таких, как культивирование растений в условиях in vitro, направленное на сокращение сроков создания ценных генотипов [1-4]. Большое значение среди биотехнологических приемов имеют клональное микроразмножение и регенерация in vitro, которые разработаны для многих видов культурных растений [5-8].

Одним из важных аспектов успешного клонального микроразмножения является подготовка эксплантов к последующему введению в культуру. Важным условием введения исходного материала в культуру in vitro является его стерилизация, по этой причине для обеззараживания первичных эксплантов проводят поверхностную обработку. Стерилизацию следует осуществлять с особой тщательностью, так как от этого зависит, будет ли эксплант развиваться или погибнет от инфекции. Растительные экспланты стерилизуют перекисью водорода, спиртом, нитратом серебра, диацидом, антибиотиками, растворами веществ, содержащими активный хлор (хлорамином, гипохлоритом $\mathrm{Na}$ ), бромом (бромной водой). Следует подбирать определенные виды и концентрации стерилизаторов, которые не повреждали бы их, а обеспечивали бы максимальную свободу от вирусов. [8-12]

Цель исследований. Изучение эфффективности стерилизующих агентов на этапе введения сортов вишни в культуру in vitro в 2018 и 2019 годах. 
Материалы и методы. Опыт проводился на базе лаборатории биотехнологии ВНИИСПК (г. Орел) в 2018 и 2019 годах.

Объектами исследования являлись сорта: Ровесница, Тургеневка, Новелла, Быстринка, Ливенская, Орлица, Бусинка.

Исходным материалом послужили экспланты, вычлененные из верхушечных и боковых почек с однолетних побегов в фазу начала выхода из периода покоя (март). Перед введением побеги ставили на отрастание.

В качестве основных стерилизующих агентов применяли: 0,1\% раствор мертиолата, $12 \%$ раствор перекиси водорода и раствор белизны (гипохлорит натрия с содержанием активного хлора 95,2 \%) в соотношении $1: 2$ и 0,1\% раствор сулемы. Стерилизацию проводили с применением магнитной мешалки для равномерного вращения объектов.

Стерилизацию проводили по следующей схеме:

1. Промывание проточной водой - 40 минут.

2. Обработка $70 \%$ раствором этилового спирта - 10 секунд.
3. Промывание автоклавированной дистиллированной водой - 10 минут.

4. Обработка основными стерилизующими растворами в 4 вариантах:

- 0,1 \% раствор мертиолата - 10 минут;

- 12 \% раствор перекиси водорода - 5 минут;

- раствор белизны (гипохлорит натрия с содержанием активного хлора 95,2 \%) в соотношении 1:2 - 5 минут;

- 0,1\% раствор сулемы - 10 минут.

5. Промывание автоклавированной дистиллированной водой 3 раза по 10 минут.

На этапе введения в культуру in vitro использовали питательную среду MS с концентрацией 6 - БАП 0,5 мг/л рН 6-6,5.

Учитывали наличие инфицированности, некроза и жизнеспособность эксплантов. Лабораторные исследования проводили по общепринятой методике $[3,8,12]$.

Результаты и их обсуждение. После 3 недель культивирования с этапа посадки на питательную среду нами учитывалось количество жизнеспособных, инфицированных и погибших эксплантов (табл.).

Результат стерилизации эксплантов при введении в культуру in vitro, \%

\begin{tabular}{|c|c|c|c|c|c|c|c|c|c|c|}
\hline \multirow[b]{2}{*}{$\begin{array}{c}\text { Стерилизующий } \\
\text { реагент }\end{array}$} & \multirow{2}{*}{ 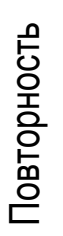 } & \multirow[b]{2}{*}{$\begin{array}{l}\text { Эффрективность } \\
\text { стерилизации, \% }\end{array}$} & \multicolumn{7}{|c|}{ Сорта* } & \multirow{2}{*}{ 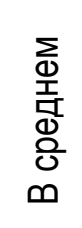 } \\
\hline & & & 1 & 2 & 3 & 4 & 5 & 6 & 7 & \\
\hline \multirow{4}{*}{ Мертиолат 0,1\% } & \multirow{2}{*}{1} & Инфрицированные & 13 & 0 & 6 & 0 & 13 & 2 & 4 & 5,4 \\
\hline & & Некроз & 0 & 0 & 1 & 0 & 1 & 0 & 0 & 0,2 \\
\hline & \multirow{2}{*}{2} & Инфрицированные & 0 & 5 & 2 & 7 & 2 & 0 & 5 & 3 \\
\hline & & Некроз & 0 & 0 & 2 & 0 & 2 & 0 & 0 & 0,6 \\
\hline \multirow{4}{*}{$\begin{array}{c}\text { Перекись водорода } \\
13 \%\end{array}$} & \multirow{2}{*}{1} & Инфрицированные & 26 & 24 & 32 & 36 & 57 & 5 & 39 & 31,2 \\
\hline & & Некроз & 2 & 0 & 0 & 0 & 13 & 0 & 0 & 2,1 \\
\hline & \multirow{2}{*}{2} & Инсрицированные & 22 & 17 & 15 & 7 & 22 & 12 & 12 & 15,2 \\
\hline & & Некроз & 0 & 0 & 0 & 0 & 2 & 0 & 0 & 0,3 \\
\hline \multirow{2}{*}{ Белизна (NaOCl) 1:2 } & \multirow{2}{*}{1} & Инфрицированные & 21 & 22 & 47 & 35 & 26 & 18 & 19 & 26,9 \\
\hline & & Некроз & 0 & 0 & 0 & 0 & 3 & 0 & 0 & 0,4 \\
\hline \multirow{2}{*}{ Сулема 0,1\% } & \multirow{2}{*}{1} & Инфицированные & 0 & 2 & 2 & 0 & 0 & 2 & 2 & 1,1 \\
\hline & & Некроз & 0 & 0 & 2 & 0 & 5 & 0 & 0 & 1 \\
\hline
\end{tabular}

*Сорта: 1 - Ровесница, 2 - Тургеневка, 3 - Новелла, 4 - Быстринка, 5 - Ливенская, 6 - Орлица, 7 - Бусинка. 
Исследование полученных данных показывает, что максимально сильнодействующим стерилизатором является 0,1\% раствор сулемы. Инфицирование эксплантов на этом стерилизаторе минимально, в среднем составило 1,1 \%. На сортах Ровесница, Быстринка и Ливенская инфицирование отсутствует полностью.

Действие препарата «Белизна» в разведении $1: 2$ оказало максимальное воздействие на сорт Орлица (18 \%) зараженных эксплантов. Значительно ниже было воздействие на сорт Новелла (47\%).

В варианте с применением 13\% раствора перекиси водорода, кроме того, отмечен выпад эксплантов от токсичного воздействия препарата на сорт Ливенская (13\%) в первой повторности. Однако следует отметить, что в этом варианте опыта во второй повторности также наблюдается разнообразная реакция сортов на использование реагента. Так, у сорта Быстринка замечен более большой выход жизнеспособных меристем (93 \%) и низкий процент погибших (0 \%) в отличие от первой повторности. У сорта Ливенская выход живых эксплантов во второй повторности значительно выше, чем в первой, на 22 и $57 \%$ соответственно.

Из таблицы видно, что наибольший выход жизнеспособных эксплантов при изучении нескольких повторностей получен в варианте с обработкой 0,1\% раствором мертиолата - в среднем 94,6 и 97 \%. При использовании стерилизаторов 0,1\% раствора мертиолата и 13\% раствора перекиси прослеживается тенденция уменьшения зараженных эксплантов с 5,4 до $3 \%$ и с 31,2 до 15,2 \% соответственно.

Выводы. Установлено, что для получения стерильных и жизнеспособных эксплантов наиболее эфффективным стерилизующим агентом для всех изученных сортов вишни оказался $0,1 \%$ раствор мертиолата $(94,6 \%)$, но в следующем проведенном исследовании наиболее эфффективным стерилизующим агентом является сулема 0,1 \% (99,9 \%). Применение других стерилизующих агентов не оказало должного воздействия.

Для сортов Орлица и Быстринка выявлена высокая эффрективность стерилизации при обработке всеми используемыми агентами.

Таким образом, была выявлена зависимость влияния различных сроков введения стерили- зующих реагентов на жизнеспособность эксплантов при их стерилизации в условиях in vitro.

\section{Литература}

1. Бутенко Р.Г. Клеточные технологии в селекционном процессе // Состояние и перспективы развития сельскохозяйственной биотехнологии: мат-лы Всесоюз. конф. Л., 1986. - С. 29-38.

2. Вечернина Н.А. Методы биотехнологии в селекции, размножении и сохранении генофонда растений. - Барнаул: Изд-во Алт. гос. ун-та, 2004. - 205 с.

3. Джигадло E.H. Методические рекомендации по использованию биотехнологических методов в работе с плодовыми, ягодными и декоративными культурами / под ред. Е.Н. Джигадло. - Орел: ВНИИСПК, 2005. $49 \mathrm{c}$.

4. Расторгуев С.Л. Культура изолированных тканей и органов в селекции плодовых растений. - Мичуринск: Изд-во МичГАУ, 2009. - 170 c.

5. Бутенко Р.Г. Биология клеток высших растений и биотехнология на их основе: учеб. пособие. - М.: ФБК-Пресс, 1999. - 160 с.

6. Джигадло Е.Н., Джигадло М.И. Размножение вишни методом верхушечных меристем // Улучшение сортимента и прогрессивные приемы возделывания плодовых и ягодных культур. - Тула: Приок. кн. изд-во, 1988. - C. 52-56.

7. Катаева Н.В., Аветисов В.А. Клональное размножение растений в культуре тканей // Культура клеток растений. - М., 1981. C. 137-149.

8. Кухарчик Н.В., Кастрицкая М.С., Семенас С.Э. [и др.]. Размножение плодовых и ягодных растений в культуре in vitro / под общ. ред. Н.В. Кухарчик. - Минск: Беларуская навука, 2016. - 208 с.

9. Лутова Л.А. Биотехнология высших растений: учебник. - СПб.: Изд-во С.-Петерб. унта, 2003. - 228 c.

10. Шевелуха В.С., Калашникова Е.А., Дегтярев С.В. [и др.]. Сельскохозяйственная биотехнология / под ред. В.С. Шевелуха. М.: Высш. шк., 1998. - 416 с. 
11. Шахов В.В., Ташматова Л.В., Мацнева О.В. Сравнительная характеристика сроков введения эксплантов черной смородины (Ribes nigrum L.) в культуру in vitro // Современное садоводство - Contemporary horticulture. 2017. - № 4. - C. 102-105.

12. Шахов В.В., Ташматова Л.В., Мацнева О.В.

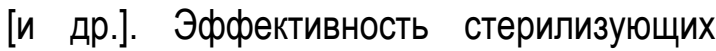
агентов при введении сортов вишни в культуру in vitro // Современное садоводство Contemporary horticulture. -2018. - № 4. C. 32-37.

\section{Literatura}

1. Butenko R.G. Kletochnye tehnologii V selekcionnom processe // Sostojanie i perspektivy razvitija sel'skohozjajstvennoj biotehnologii: mat-ly Vsesojuz. konf. - L., 1986. - S. 29-38.

2. Vechernina N.A. Metody biotehnologii $\mathrm{V}$ selekcii, razmnozhenii i sohranenii genofonda rastenij. - Barnaul: Izd-vo Alt. gos. un-ta, 2004. - 205 s.

3. Dzhigadlo E.N. Metodicheskie rekomendacii po ispol'zovaniju biotehnologicheskih metodov $\checkmark$ rabote s plodovymi, jagodnymi i dekorativnymi kul'turami / pod red. E.N. Dzhigadlo. Orel: VNIISPK, 2005. - $49 \mathrm{~s}$.

4. Rastorguev S.L. Kul'tura izolirovannyh tkanej i organov $\mathrm{v}$ selekcii plodovyh rastenij. Michurinsk: Izd-vo MichGAU, 2009. - 170 s.

5. Butenko R.G. Biologija kletok vysshih rastenij i biotehnologija na ih osnove: ucheb. posobie. M.: FBK-Press, 1999. - $160 \mathrm{~s}$.
6. Dzhigadlo E.N., Dzhigadlo M.I. Razmnozhenie vishni metodom verhushechnyh meristem // Uluchshenie sortimenta i progressivnye priemy vozdelyvanija plodovyh i jagodnyh kul'tur. Tula: Priok. kn. izd-vo, 1988. - S. 52-56.

7. Kataeva N.V., Avetisov V.A. Klonal'noe razmnozhenie rastenij $v$ kul'ture tkanej /I Kul'tura kletok rastenij. - M., 1981. - S. 137149.

8. Kuharchik N.V., Kastrickaja M.S., Semenas S.Je. [i dr.]. Razmnozhenie plodovyh i jagodnyh rastenij $v$ kul'ture in vitro / pod obshh. red. N.V. Kuharchik. - Minsk: Belaruskaja navuka, 2016. - $208 \mathrm{~s}$.

9. Lutova L.A. Biotehnologija vysshih rastenij: uchebnik. - SPb.: Izd-vo S.-Peterb. un-ta, 2003. $-228 \mathrm{~s}$.

10. Sheveluha V.S., Kalashnikova E.A., Degtjarev S.V. [i dr.]. Sel'skohozjajstvennaja biotehnologija / pod red. V.S. Sheveluha. M.: Vyssh. shk., 1998. - $416 \mathrm{~s}$.

11. Shahov V.V., Tashmatova L.V., Macneva O.V. Sravnitel'naja harakteristika srokov vvedenija jeksplantov chernoj smorodiny (Ribes nigrum L.) v kul'turu in vitro // Sovremennoe sadovodstvo - Contemporary horticulture. 2017. - № 4. - C. 102-105.

12. Shahov V.V., Tashmatova L.V., Macneva O.V. [i dr.]. Jeffektivnost' sterilizujushhih agentov pri vvedenii sortov vishni $v$ kul'turu in vitro // Sovremennoe sadovodstvo - Contemporary horticulture. - 2018. - № 4. - C. 32-37. 